\title{
Tratamento fisioterapêutico na disfunção temporomandibular: um estudo de caso
}

Physical therapy treatment for

temporomandibular disorders:

A Case Study

FisiSenectus. Unochapecó Ano 1 - Edição especial - 2013 p. 109-117

\begin{abstract}
Rodrigo Arenhart
Fisioterapeuta, mestre em Ciências do Movimento Humano - Biomecânica (Udesc), professor do Centro de Pós-graduação lato sensu Odontocenter/Unicsul dos cursos de Prótese, Ortodontia e Endodontia, professor do curso de Pós-graduação lato sensu em Fisioterapia Ortopédica e Traumatológica pela ACE, URI, Uningá, FSG, professor curso Graduação em Fisioterapia da URI
\end{abstract}

\section{Ricardo Lazarotto}

Fisioterapeuta, graduado pela Universidade Comunitária da Região de Chapecó (Unochapecó), especialista em Fisioterapia em Ortopédica e Traumatológica pela Associação Catarinense de Ensinio (ACE) em parceria com Instituto de Ortopedia e Traumatologia de Passo Fundo (IOT), ricardo@lazarotto.com

\section{Kélin Thomé}

Fisioterapeuta, graduado pela Universidade Comunitária da Região de Chapecó (Unochapecó), especialista em Fisioterapia em Ortopédica e Traumatológica pela Associação Catarinense de Ensinio (ACE) em parceria com Instituto de Ortopedia e Traumatologia de Passo Fundo (IOT), kelinthome@hotmail.com

Artigo científico apresentado ao curso de Especialização, lato sensu, em Fisioterapia Ortopédica e Traumatológica, do curso de Fisioterapia, da Faculdade Guilherme Guimbala, mantida pela Associação Catarinense de Ensino, em parceria com o Instituto de Ortopedia e Traumatologia de Passo Fundo (RS) como requisito parcial para obtenção do certificado de especialista (2012).

\section{Resumo}

Introdução: Sabe-se que articulação temporomandibular (ATM) é a mais complexa do corpo humano, sendo assim está suscetível a diversas alterações, dentre estas a subluxação articular. Objetivo: Verificar o efeito do tratamento fisioterapêutico na disfunção temporomandibular. Materiais e métodos: Trata-se de uma pesquisa do tipo estudo de caso na qual foi avaliada e tratada uma paciente com diagnóstico odontológico de subluxação da ATM, com queixas de dor intensa, estalidos, cefaleia. Sujeito do sexo feminino, 28 anos, casada. Foi realizada avaliação através de um Questionário para avaliação de disfunção temporomandibular, escala análogo visual da dor EVA, e uma avaliação postural. Foram realizados vinte atendimentos, dois semanais com duração de 50 minutos. 
Resultados e Considerações finais: Observou-se que exercícios para alívio de dor (liberação de pontosgatilho), estimulação elétrica transcutânea (TENS), alongamentos e principalmente fortalecimento muscular apresentam bons resultados no tratamento de subluxação de ATM.

\title{
Palavras-chave
}

Disfunção temporomandibular. Subluxação temporomandibular. Fisioterapia.

\begin{abstract}
Introduction: It is known that the Temporomandibular Joint (TMJ) is the most complex joint in the human body, and thus is susceptible to various changes among these joint subluxation. Objective: To determine the effect of physiotherapy in temporomandibular dysfunction. Materials and Methods: This is a survey of the case study where it was evaluated and treated a patient with a dental diagnosis of subluxation of the TMJ, with complaints of pain, popping, headache. Female subject, 28 years, married. Evaluation was performed using a questionnaire for assessment of temporomandibular dysfunction, visual analog scale for pain VAS, and a postural assessment. Calls were made twenty two weekly lasting fifty minutes. Results and Final Thoughts: It was observed that exercises for pain relief (release trigger points), Transcutaneous Electrical Stimulation (TENS), stretching and strengthening exercises have mostly good results in the treatment of subluxation of TMJ.
\end{abstract}

\section{Keywords}

temporomandibular disorders. Temporomandibular subluxation. Physiotherapy.

\section{Introdução}

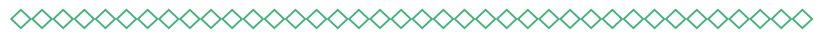

A articulação temporomandibular (ATM) é considerada a mais complexa do corpo humano, sendo a única articulação móvel do crânio, e sua complexidade está relacionada à possibilidade de realizar movimentos rotacionais e translacionais devido à articulação dupla do côndilo ${ }^{1}$.

0 fato de a ATM apresentar duas articulações (côndilos) conectadas a mandíbula exige que estas trabalhem simultaneamente, dependendo de um processo harmônico entre a oclusão dental, o equilíbrio neuromuscular e a própria articulação. Devido a sua complexidade articular, está vulnerável a alterações funcionais ou patológicas, ocasionado desarranjos deste sistema ${ }^{1,2}$.

A disfunção temporomandibular (DTM) constitui de uma desarmonia no sistema estomatognático, podendo ocorrer envolvimento e prejuízo na articulação temporomandibular (ATM), nos músculos mastigatórios e outras estruturas adjacentes. Intimamente relacionadas, encontram-se as condições músculo-esqueléticas da região mandibular e cervical presentes na DTM, sendo as maio- res causas de dor não dental na região orofacial, interferindo amplamente na qualidade de vida dos indivíduos ${ }^{3}$.

A etiologia das disfunções temporomandibulares é multifatorial, correlacionando-se com alterações oclusais, hábitos parafuncionais (como bruxismo e "apertamento" dentário), estresse, ansiedade, má postura, microtraumas repetitivos, anormalidades no disco intra-articular, hiperatividade muscular ${ }^{4}$. E ainda por hipermobilidade articular, que pode se associar com patologias musculares e articulares da articulação temporomanbidular ${ }^{5}$.

De acordo com dados epidemiológicos relatados por Carrara, Conti e Barbosa ${ }^{6}$, de $40 \%$ a $75 \%$ da população apresentam ao menos um sinal de DTM, como ruídos na ATM, e 33\% pelo menos um sintoma, como dor na face ou na articulação temporomandibular. No Brasil, em estudos realizados em amostras populacionais concluiu-se que $37,5 \%$ da população apresentavam ao menos um sintoma de DTM. Entre estudantes universitários, estima-se que $41,3 \%$ a $68,6 \%$ apresentem algum sinal ou sintoma de DTM. 
Ainda para Pasinato et al. ${ }^{7}$, muitos pacientes se tornam assintomáticos e procuram tratamento somente quando ocorre uma subluxação decorrente de uma excessiva abertura bucal, sendo causada pela frouxidão ligamentar tendo como resultado alterações degenerativas que podem se manifestar em desarranjos internos e inflamação articular.

Para minimizar os efeitos causados pela DTM a fisioterapia torna-se fundamental e parte integrante no tratamento destes pacientes. 0 objetivo do tratamento fisioterapêutico é diminuir ou eliminar os sinais e sintomas e normalizar a função da articulação temporomandibular. Para isso, é necessária uma boa avaliação funcional e postural, ou seja, o individuo deve ser visto como um todo. Sendo assim, tem-se como objetivo do estudo verificar o efeito do tratamento fisioterapêutico na disfunção temporomandibular através de um estudo de caso.

\section{Materiais e métodos}

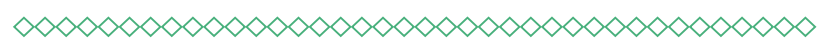

Trata-se de uma pesquisa do tipo estudo de caso em que se avaliou um paciente com diagnostico de Disfunção Temporomandibular e tratado no serviço de fisioterapia na Clínica de Fisioterapia Corpo e Mente no município de Tunápolis (SC).

O sujeito assinou um Termo de Consentimento Livre e Esclarecido respeitando os princípios básicos da bioética, conforme Resolução 196/96 do Conselho Nacional de Saúde, sendo aprovado pelo Comitê de Ética em Pesquisa da Universidade Regional Integrada (URI) - campus de Erechim (RS): CEP/URI 097/CTH/12 ${ }^{8}$.

0 sujeito A.S., sexo feminino, 28 anos, casada, administradora de empresa. Apresenta diagnóstico odontológico de subluxação de ATM. Tem como queixa principal dor aos mínimos esforços (abertura bucal, bocejo, mordida), apresenta cefaleia, relata dor intensa há aproximadamente quarenta dias.

Apresenta sintomas otológicos como estalidos em articulação direita quando abre a boca, e dor nos músculos da face após mastigação.

A paciente respondeu um Questionário para Avaliação de Disfunção Temporomandibular re- comendado pela Academia Americana de dor Orofacial ${ }^{9}$, sendo composto por perguntas fechadas para classificar a origem da DTM, classificando-as como desordem muscular, articular ou mista. Após preenchimento do questionário, verificou-se que a paciente apresentava DTM de origem mista. Também foi utilizada a Escala Análogo Visual da dor, na qual a paciente pontua sua dor em um nível de 0 a 10, sendo 0 a 2 nível leve, 3 a 7 nível moderado e 8 a 10 nível intenso. Uma avaliação postural, em que se avaliou o grau de abertura da articulação temporomandibular, estalidos, lateralidade grau de dor nos principais músculos da mastigação e também o grau de força muscular nos movimentos da ATM.

Para realizar a mensuração de abertura e lateralidade da boca foi utilizado um goniômetro da marca ISP. Para ausculta da articulação temporomandibular foi utilizado um estetoscópio da marca Premium.

Foram realizados vinte atendimentos sendo 2 sessões semanais com duração de 50 minutos cada. 0 primeiro atendimento foi realizado avaliação da paciente que recebeu informações educacionais em relação às causas da subluxação e quais movimentos a provocam, por exemplo, restringindo a abertura da boca, dar risada, bocejar. Em seguida foram realizados exercícios de relaxamento da coluna cervical, liberação de tensão (ponto gatilho) dos músculos tensos devido à hiperatividade destes e somente nos dois primeiros atendimentos foi utilizado eletroanalgesia com TENS, pois a paciente relatava muito desconforto com o uso do aparelho, utilizando com maior ênfase a terapia manual (liberação de pontos gatilhos) e alongamentos dos músculos masseteres, pterigóideos laterais e mediais para o alívio do quadro álgico e foram realizados em todos os atendimentos para manter integridade musculotendinea. Quando a paciente relatou melhora do quadro álgico, iniciaram-se os exercícios de fortalecimento.

Inicialmente, foram realizado exercício isométrico ativo com 3 séries de 30 segundos, em que paciente deveria resistir as tentativas do terapeuta de mover para lado contrário do qual se queria fortalecer (fortalecimento/estabilização capsular) pedindo para a paciente abrir a boca, fechar, lateralizar a direita e esquerda. Em seguida paciente 
foi instruída a mascar chiclete. Por fim, utilizando borracha de látex, era solicitando a paciente que mordesse esta e também mantivesse a força resistindo à abertura da boca pela terapeuta segurando e tracionando a borracha. No vigésimo atendimento foi realizada a reavaliação da paciente para análise dos dados e resultados. A avaliação e tratamento foi realizado pelo mesmo profissional.

\section{Resultados}

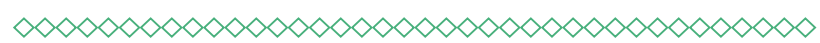

No que diz respeito a Tabela 1 , apresenta a comparação da dor geral, sendo pontuada como 8 na avaliação e 3 na reavaliação. Ao realizar a palpação dos músculos faciais, obteve-se na avaliação e reavaliação do masseter 7 reavaliação 3 , temporal 8 reavaliação 2, esternocleidomastóideo 5 reavaliação 0 , trapézio 0 , reavaliação 0 , coluna cervical (paravertebrais) 3 reavaliação 1, pterigoideo lateral 7 reavaliação 2 , pterigoideo medial 8 reavaliação 2, escalenos 5 reavaliação 0 , suboccipitais 4 reavaliação 1 .

Quanto à Tabela 2, trata-se do grau de mobilidade articular da ATM, apresentando a abertura máxima da boca avaliada em $55 \mathrm{~mm}$ e na reavaliação $35 \mathrm{~mm}$; a lateralidade a direita avaliada em $25 \mathrm{~mm}$ e reavaliada em $35 \mathrm{~mm}$, já na lateralidade a esquerda apresentou $20 \mathrm{~mm}$ na avaliação e $30 \mathrm{~mm}$ na reavaliação.

$\mathrm{Na}$ Tabela 3 se expressa a ausculta da ATM na abertura e fechamento na boca. Na avaliação apresentou estalidos ao final da abertura bucal (caracterizando grau 3) e na reavaliação apresentou estalido ao início da abertura (caracterizando grau 1).

A Tabela 4 apresenta a comparação de força muscular na avaliação e reavaliação. Os músculos da abertura da boca maxilar apresentou grau 4 na avaliação e grau 5 na reavaliação, pterigoideo lateral grau 4 na avaliação e grau 5 na reavaliação. Nos músculos do fechamento da boca masseter na avaliação grau 4 e na reavaliação grau 5, temporal na avaliação grau 4 e na reavaliação grau 5, pterigoideo medial na avaliação grau 4 e na reavaliação 5 .

Quanto a Tabela 5, se compara a ADM da coluna cervical na avaliação e na reavaliação nos movimentos de flexão, extensão, inclinação lateral para a esquerda e direita.

\section{Discussão}

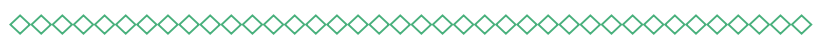

No presente estudo de caso foi realizado o tratamento da DTM com objetivo de diminuir/eliminar os sinais e sintomas característicos e retomar a função normal da articulação. 0 quadro álgico foi avaliado de acordo com a Escala Analógica Visual da Dor (EVA), no qual a paciente apresentou grau 8 na avaliação e grau 3 após o tratamento fisioterapêutico.

De acordo com Torres et al. ${ }^{10}$, ao aplicar de um protocolo semelhante ao deste estudo, relatou-se uma melhora de $96,5 \%$ da amostra com o tratamento fisioterapêutico contra 30,9\% da amostra submetida apenas ao tratamento odontológico.

Devido à natureza dos sinais e sintomas das disfunções temporomandibulares, tratamentos simples e conservadores vêm ganhando preferência aos invasivos. No caso do tratamento fisioterapêutico estão incluídos os exercícios de relaxamento, alongamento, ultrassom, massagem, TENS, estabilização oclusal e cinesioterapia, complementando com uso de farmacoterapia e infiltração anestésica realizado pelo profissional pertinente, têm sido indicados por demonstrar excelentes resultados no controle da dor em associação a um efetivo tratamento odontológico. 0 tratamento conservador deve oferecer ao paciente a redução de suas limitações, bem como o desconforto ocasionado pela dor, visando melhorar sua qualidade de vida ${ }^{11,12}$.

Os exercícios de alongamentos, de acordo com Gurjão et $a l .^{13}$, adicionado ao protocolo de atendimento, propiciam um efeito analgésico, pois após o alongamento ocorre uma hiperemia e um aumento na velocidade do fluxo sanguíneo nos capilares próximos a região alongada, o que auxilia no alívio da dor. Fato este que justifica a diminuição da dor de toda musculatura como mostra a tabela 1.

Ao avaliar a mobilidade articular, a paciente apresentou $55 \mathrm{~mm}$ de abertura bucal e no vigésimo atendimento diminuiu para $35 \mathrm{~mm}$, ou seja, o risco para subluxação diminuiu bem como a lateralidade a direita que era de $25 \mathrm{~mm}$ na avaliação passou para $35 \mathrm{~mm}$ na reavaliação, já na lateralidade a esquerda apresentou $20 \mathrm{~mm}$ na avaliação e $30 \mathrm{~mm}$ na 
reavaliação o que facilita a mastigação da paciente para ambos os lados diminuindo a abertura bucal.

Em estudo realizado por Pasinato 7 , condiz com o presente estudo, relatando a grande frequência de hipermobilidade articular relacionado às DTMs, ocasionando possíveis luxações e subluxações mandibulares.

Segundo Garcia ${ }^{14}$, a fisioterapia tem como objetivo evitar a cirurgia, reposicionar a mandíbula ao crânio e com isso melhorar a função, minimizar a dor muscular, melhorar a amplitude de movimento, melhorar sua postura, reeducar o paciente em relação ao posicionamento correto da mandíbula, reduzir a inflamação, reduzir a carga na articulação temporomandibular e fortalecer o sistema músculo esquelético.

Na avaliação por ausculta da ATM, a paciente apresentou estalidos ao final da abertura bucal no lado direito e na reavaliação apresentou estalido ao início da abertura no mesmo lado, ou seja, diminui o grau de disfunção temporomandibular. A subluxação ocorre na ausência de qualquer condição patológica e representa um movimento articular normal.

Uma ATM que apresenta configuração anatômica de sua eminência articular em declive posterior curto e inclinado seguido de um declive anterior mais longo tende a subluxar ${ }^{9}$. 0 sintoma da subluxação é relatado pelo paciente como um "deslocamento" toda vez que se abre bastante a boca ou se move a mandíbula lateralmente, podem também relatar estalido articular. 0 som articular é descrito como um ruído surdo (baque). Clinicamente, avalia-se a subluxação observando a abertura máxima da boca, caso esteja presente, no último estágio da abertura, o côndilo "pula" para frente, deixando uma pequena depressão atrás de $\mathrm{si}^{15}$. Os dados descritos na literatura são encontrados claramente na ficha de avaliação da paciente, em que relatou estalidos e o desencaixe da articulação.

Frequentemente, o estalido é único sintoma da subluxação, aproximadamente $20 \%$ da população apresenta o sinal de forma assintomática ${ }^{16}$.

0 tratamento da subluxação é realizando inicialmente de modo conservador (fisioterapia e ou próteses dentárias), não havendo melhora dos sin- tomas faz-se necessário o tratamento cirúrgico. 0 tratamento começa com a educação do paciente com relação às causas da subluxação e quais movimentos a provocam, por exemplo, restringindo a abertura da boca, dar risada, bocejar ${ }^{15,11}$.

Diferente de estudos encontrados na literatu$\mathrm{ra}$, o presente estudo relata o fortalecimento da musculatura mastigatória no tratamento da DTM. Devido às desordens da subluxação côndilar, é importante fortalecer os músculos e ligamentos que compõem a ATM, objetivando a estabilização articular através do aumento do trofismo de forma equilibrada, pois a subluxação ocorre quando há presença de fraqueza da musculatura envolvida nos movimentos da ATM.

Entretanto, Matta ${ }^{17}$ apresenta bons resultados no tratamento das desordens da articulação temporomandibular por meio de protocolo fisioterapêutico com utilização de meios térmicos (crioterapia e calor), ultrassom e laser, terapia manual e exercícios isométricos leves contra resistidos utilizados para evitar a luxação propriamente dita foram os exercícios isométricos como o autor relata que tem eficácia.

De acordo com um estudo realizado por Milanesi et al. ${ }^{18}$, a ADM cervical depende de inúmeras variáveis, como idade, gênero, dimensão do pescoço e dor. Relatam ainda que compensações podem representar um mecanismo necessário para fornecer estabilidade para os sistemas mandibular e cervical, sendo necessário incluir a avaliação clínica da coluna cervical em indivíduos com DTM.

Podem ser considerados valores normais de amplitude de movimento, estabelecidos por Magee $^{19}$, a flexão da coluna cervical normal $0^{\circ}-80-90^{\circ}$, extensão $0^{\circ}-70^{\circ}$, flexão lateral da coluna cervical $0^{\circ}-20-45^{\circ}$ e a rotação da coluna cervical $0^{\circ}-70-90^{\circ}$. Após o tratamento fisioterapêutico observou-se aumento da amplitude de movimento, em que se consta $83^{\circ}$ de flexão cervical, $75^{\circ}$ de extensão, $60^{\circ}$ inclinação lateral para direita e esquerda, $80^{\circ} \mathrm{em}$ rotação lateral à direita e $70^{\circ}$ em rotação lateral à esquerda se apresentando dentro dos limites anatômicos, e em alguns movimentos, ultrapassando os valores de referência observando um aumento considerável da mobilidade.

De acordo com revisão da literatura realizada por Amantéa et al. ${ }^{20}$, é fundamental a avaliação 
postural em pacientes portadores da DTM, pois devido a proximidade dos sistemas há uma relação íntima entre a articulação temporomandibular e a coluna cervical. Distúrbios do aparelho estomatognático como a hiperatividade muscular podem levar a anteriorização da cabeça.

A atividade aumentada da musculatura mastigatória interfere nos músculos de contra apoio (esternocleideomastoide e trapézio), que leva a um encurtamento dos músculos posteriores do pescoço e alongamento dos anteriores. Essa posição anteriorizada da cabeça pode levar a um distúrbio de posicionamento e funcionamento mandibular que pode gerar tensão na musculatura mastigatória caracterizando-se a DTM 21,22.

Em nosso estudo de caso pode se observar os dados condizentes com a literatura, verificando que o tratamento fisioterapêutico na coluna cervical visou o controle álgico, pois a paciente apresentava a força e mobilidade articular condizente com a biomecânica.

\section{Conclusão}

$\infty \times \infty \times \infty \times \infty \times \infty \times \infty \times \infty \times \infty \times \infty \times \infty \times \infty \times \infty \infty$

Verificou-se neste estudo que a fisioterapia no tratamento conservador nas DTMs apresenta grande eficácia. 0 presente estudo de caso demonstra que houve evolução benéfica do quadro clínico de fraqueza muscular dos músculos envolvidos na ATM através de exercícios de liberação de pontos gatilhos, alongamentos e principalmente fortalecimento da musculatura mastigatória, que fez com que a abertura da boca diminuísse, evitando a recidiva da subluxação.

Dentro da abordagem fisioterapêutica também é possivel perceber que as formas de tratamento são diversas e o profissional deve elencar as técnicas que julga mais favoráveis para tratar seu paciente. Entre os constantes estudos na área da fisioterapia, percebe-se que há uma diminuição da aplicação de protocolos de tratamento fechados, passando a utilizar protocolos de tratamentos personalizados de acordo com as necessidades do paciente tornando-se mais eficaz e com menor probabilidade de falha, pois cada paciente possui suas particularidades e nem sempre se tem bons resultados utilizando a mesma forma de tratamento para vários pacientes.

Sugere-se que mais estudos como este sejam realizados, pois a literatura não apresenta formas de tratamento específicas para a subluxação, mas sim relatam o tratamento conservador das DTMs de uma maneira geral, que, normalmente apresentam a dificuldade na abertura bucal, na qual ocorre disfunção contraria na subluxação.

\section{Referências}

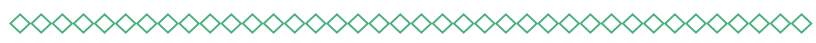

1. Donnarumma MDC, Muzilli CA, Ferreira C, Nemr K. Disfunções temoromandibulares: Sinais, sintomas e abordagem multidisciplinar. Rev. CEFAC. 2010;12(5):788-94.

2. Rodrigues BD, Almeida AFN, Berni KCS, Pedroni CR, Gonçalves RN, Bérzin F. Utilização de diferentes estimulações elétricas para 0 tratamento da dor em mulheres com disfunção temporomandibular. Rev. Bras Fisioter. 2008;12(6):476-81.

\section{Taucci RA, Bianchini EMG. Variação da} interferência das disfunções temoporomandibular na articulação da fala: queixas e caracterização dos movimentos mandibulares. Rev. Soc Bras Fonoaudiol. 2007;12(4):274-80.

4. Silva MMA, Ferreira AT, Migliorucci RR, Nari Filho $H$, Berretin-Felix $G$. Influência do tratamento ortodôntico-cirúrgicos nos sinais e sintomas de disfunção temporomandibulares em indivíduos com deformidades dentofocais. Rev. Soc Bras Fonoaudiol. 2011;16(1):80-84.

5. Ávila Júnior ET, Flecha OD, Oliveira Filho PM. Prevalência de sintomatologia para a Disfunção Temporomandibular (DTM) em estudantes de Odontologia e sua associação com a Hipermobilidade Condilar da Articulação Temporomandibular (ATM). Arquivos em Odontologia. 2009;45(1):16-21.

6. Carrara SV, Conti PCR, Barbosa JS. Termo do $1^{\circ}$ Consenso em Disfunção Temporomandibular e Dor Orofacial. Dental Press J Orthod. 2010;15(3):114-20. 
7. Pasinato F, Souyza JA, Corrêa ECR, Silva, AMT. Disfunção têmporo-mandibular e hipermobilidade articular generalizada: aplicação de critérios diagnósticos. Braz. j. otorhinolaryngol. 2011;77(4):418-25.

8. Vieira S, Hossne WS. Metodologia científica para a área de saúde. Rio de Janeiro: Campus; 2003.

9. Okeson JP. Tratamento das Desordens Temporomandibulares e Oclusão. 4a ed. São Paulo: Artes Médicas; 2000.

10. Torres F, Campos LG, Fillipini HF, Weigert KL, Dalla Vecchia GF. Efeitos dos tratamentos fisioterapêuticos e odontológicos em pacientes com disfunção temporomandibular. Fisioter. mov. 2012;25(1):117-25.

11. Franco AL, Zamperini CA, Salata DC, Silva EC, Júnior WA, Camparis CM. Fisioterapia no tratamento da dor orofacial de pacientes com disfunção temporomandibular crônica. Revista Cubana de Estomatología. 2011;48(1):56-61.

12. Kisner C, Colby LA. Exercícios Terapeuticos Fundamentos e Tecnicas. 5a ed. São Paulo: Manole; 2009.

13. Gurjão ALD, Carneiro NH, Gonçalves R, Moura RF, Gobbi S. Efeito agudo do Alongamento Estático na Força Muscular de Mulheres Idosas. Rev Bras Cineantropom Desempenho Hum. 2010;12(3):195-201.

14. Garcia JD, Oliveira ACA. Fisioterapia nos sinais e sintomas da disfunção temporomandibular (ATM). Revista Hórus. 2011;5(1):113-24.

15. Bernardino Júnior R, Teixeira M, Goulart LV, Guedes LI, Costa EMC. Avaliação de Técnica Alternativa Aplicada ao Tratamento Imediato de Luxação Espontânea da Articulação Têmporo Mandibular. Biosci. J. 2006;22(3):105-11.
16. Manual Merck Saúde para a família. Capítulo 96 - Distúrbios da Articulação temporomandibular. Seção 8 - Distúrbios da Boca e Dentes. Disponível em:nhttp://mmspf. msdonline.com.br/pacientes/manual_merck/ secao_08/cap_096.html. Acesso em: 26/06/2012 às 23:16.

17. Matta MAP. Uma Proposta de Abordagem Fisioterapêutica nas Desordens da Articulação Temporomandibular [dissertação]. Campinas: Universidade Estadual de Campinas, Faculdade de Ciências Médicas; 2002.

18. Milanesi JM, Côrrea ECR, Borin GS; Souza JA, Pasinato F. Atividade elétrica dos músculos cervicais e amplitude da coluna cervical em índividuos com e sem DTM. Fisioter Pesqui. 2011;18(4):317-22.

19. Magee DJ. Coluna Cervical. In: Magee DJ. Avaliação Musculoesquelética. 3a ed. São Paulo: Manole; 2002. p. 105-157.

20. Amantéa DV, Novaes AP, Campolongo GD, Barros T. A Importância da Avaliação Postural em Pacientes com Disfunção Temporomandibular. Acta Ortop Bras. 2004;12(3):155-9.

21. Munhoz WC. Avaliação global ortostática de indivíduos portadores de Distúrbios internos da Articulação Temporomandibular: Aplicabilidade de métodos clínicos, fotográficos e radiográficos [dissertação]. São Paulo: Universidade de São Paulo; 2001.

22. Rego FAC, Restani AVC, Gandelman H. Estudo da relação entre a disfunção da Articulação Temporomandibular e as alterações posturais. Rev Odontol UNICID. 2001;13(2):125-33. 


\section{Anexos}

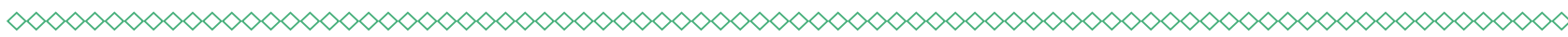

Tabela 1 - Comparação da dor a palpação na avaliação e reavaliação

\begin{tabular}{lcc}
\multicolumn{1}{c}{ Item } & Pré & Pós \\
Quadro álgico geral (EVA) & 8 & 3 \\
\hline Músculos & 7 & 2 \\
Masseter & 8 & 2 \\
Temporal & 5 & 0 \\
Esternocleidomastóideo & 3 & 0 \\
Trapézio & 3 & 1 \\
Coluna Cervical (Paravertebrais) & 7 & 2 \\
Pterigóideo Lateral (palpação intraoral) & 8 & 2 \\
Pterigóideo Medial (palpação intraoral) & 5 & 0 \\
Escalenos & 4 & 1 \\
Suboccipitais & & 2
\end{tabular}

Fonte: elaboração dos autores.

Tabela 2 - Comparação da mobilidade articular na avaliação e reavaliação

\begin{tabular}{lcc}
\multicolumn{1}{c}{ Item } & Pré & Pós \\
Abertura máxima da boca & $55 \mathrm{~mm}$ & $35 \mathrm{~mm}$ \\
Lateralidade da boca à direita & $25 \mathrm{~mm}$ & $35 \mathrm{~mm}$ \\
Lateralidade da boca à esquerda & $20 \mathrm{~mm}$ & $30 \mathrm{~mm}$ \\
\hline
\end{tabular}

Fonte: elaboração dos autores.

(clique para voltar ao texto)

Tabela 3 - Comparação da ausculta da ATM na avaliação e reavaliação

\begin{tabular}{lcccc} 
& \multicolumn{2}{c}{ Pré-tratamento } & \multicolumn{2}{c}{ Pós-tratamento } \\
Ausculta & Direita & Esquerda & Direita & Esquerda \\
\hline Abertura & Sim ao final & Ausente & Sim ao início & Ausente \\
Fechamento & Ausente & Ausente & Ausente & Ausente \\
\hline
\end{tabular}

Fonte: elaboração dos autores. 
Tabela 4 - Comparação do grau de força muscular

Músculos da abertura da boca

$\begin{array}{lll}\text { Maxilar } & 4 & 5 \\ \text { Pterigóideos Lateral } & 4 & 5\end{array}$

\section{Músculos do fechamento da boca}

Masseter

4

5

Temporal

4

5

Pterigóideo medial

4 5

Fonte: elaboração dos autores.

(clique para voltar ao texto)

Tabela 5 - Comparação da ADM cervical na avaliação e reavaliação

\begin{tabular}{lcc} 
& Pré-tratamento & Pós-tratamento \\
Flexão & $40^{\circ}$ & $83^{\circ}$ \\
Extensão & $75^{\circ}$ & $75^{\circ}$ \\
Inclinação Lateral para a Esquerda & $55^{\circ}$ & $60^{\circ}$ \\
Inclinação Lateral para a Direita & $60^{\circ}$ & $60^{\circ}$ \\
Rotação para Direita & $80^{\circ}$ & $80^{\circ}$ \\
Rotação para Esquerda & $50^{\circ}$ & $70^{\circ}$ \\
\hline
\end{tabular}

Fonte: elaboração dos autores. 